\title{
Morse taper internal connection implants: would abutment reseating influence retention?
}

\author{
Stenio Cardoso Rabelo ${ }^{1}$, Sheyla Viana Omonte ${ }^{2}$, Sarita Pires Vieira², \\ Wellington Correa Jansen², Paulo Isaias Seraidarian²
}

${ }^{1}$ Private Practice, Divinópolis, MG, Brazil

${ }^{2}$ Pontifícia Universidade Católica de Minas Gerais - PUC MINAS, School of Dentistry, Department of Restorative Dentistry, Belo Horizonte, MG, Brazil

Received for publication: May 20, 2015 Accepted: September 22, 2015

Correspondence to: Paulo Isaias Seraidarian Departamento de Odontologia Pontifícia Universidade Católica de Minas Gerais Avenida Dom José Gaspar, 500. Prédio 46. Sala

101. Coração Eucarístico. CEP: 30535-901 Belo Horizonte, MG, Brasil Phone: +55 3133194414 Fax: +55 3133194414

E-mail: seraidarian@gmail.com

\begin{abstract}
Aim: To investigate whether the removal and reseating of the abutment influences the retention of Morse taper implant system. Methods: Two Morse taper implant systems were selected: Bicon Dental Implant ${ }^{\mathrm{TM}}$ system (Bicon, LLC, Boston, MA, USA) and Kopp Implant ${ }^{\oplus}$ system (Kopp ${ }^{\circledR}$, Curitiba, PR, Brazil). In both systems, the abutment is connected to the implant with a locking taper. To seat the abutment, the same vertical force was applied in both systems. It was measured the compressive force necessary to engage effectively the locking taper connection and the tensile force to displace it. Results: The compressive force was determined by four activations in each abutment-implant set, and the sum of these forces was $21 \mathrm{~N}$ and $17 \mathrm{~N}$ in the Bicon $^{\top \mathrm{M}}$ and Kopp ${ }^{\circledR}$ systems, respectively. Next, a tensile test was performed, revealing that the Bicon ${ }^{\top \mathrm{M}}$ system presented a $208 \mathrm{~N}$ resistance, whereas it was $194 \mathrm{~N}$ in the Kopp ${ }^{\circledR}$ system. Other three rounds of compression and tensile loads were applied, removing and reseating the abutment. We obtained the following tensile values: $367 \mathrm{~N}, 500 \mathrm{~N}$ and $756 \mathrm{~N}$ in the Bicon ${ }^{\mathrm{TM}}$ System and 336 $\mathrm{N}, 360 \mathrm{~N}$ and $420 \mathrm{~N}$ in the Kopp ${ }^{\circledR}$ system. Conclusions: When the sets were subjected to repeated rounds of compressive and tensile forces, displacing and reseating the abutment, the tensile value increased.
\end{abstract}

Keywords: dental implant-abutment design; dental implants; compressive strength; tensile strength.

\section{Introduction}

The search for an optimal implant configuration has led to various internal geometries with different prosthetic platforms ${ }^{1}$. The goal is to reduce the fatigue on the setting screws and obtain a better biological seal, mechanical strength and aesthetics $^{2-5}$.

One of the main challenges confronting implant dentistry today is to achieve an implant-abutment connection that satisfactorily meets the principles of biomechanics. This difficulty is often due to loosening or even breaking of the fixation screw $^{6-8}$. Screwless implant systems have several advantages, such as the possibility of appropriate cervical region aesthetics and fewer prosthetic components. It leads to cost reduction, simpler clinical procedures, and greater fracture resistance of the prosthetic component ${ }^{3-4,9-10}$. Moreover, the Morse cone design platform offers a greater and stronger implant-abutment interface, yielding a better fit between these elements. It allows gap reduction and increased micromovement resistance. It also provides joint stability ${ }^{5}$ due to the high frictional force created by the locking taper, which is produced by the pressure of two 
sliding surfaces. As a result, surface oxide layers break down, a phenomenon known as cold welding ${ }^{11}$. Therefore, there is less risk of gaps between the implant and abutment, producing a seal proven to delay or even prevent bacterial invasion $^{12-14}$ and to be clinically reliable ${ }^{15}$. A recent study on implant components stability demonstrated that loosening in sets with internal tapered connections is less frequent than in sets with other connection types ${ }^{16}$.

Although high success rate in Morse taper implant

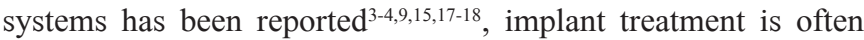
hindered by complications ${ }^{1,19}$. Abutment displacement may occur $^{9,17}$. Furthermore, removing the abutment-crown complex may be required. This raises the question of whether the reinsertion procedure will jeopardize the system retention. Additionally, doubts were raised regarding quantification of forces applied during installation of frictional systems ${ }^{19}$. It should be noted that in Morse taper systems, the manufacturer's recommendation is to insert, align and then put the abutment in place by seating taps intermittently applied using a weight load. This load is applied to achieve the required mechanical friction between the external wall of the abutment and the internal wall of the implant, which results in high contact pressure ${ }^{1}$. In screw-retained systems, the screw is tightened with a torque established by the manufacturer ${ }^{19}$. To the best of our knowledge, in the Morse taper system there is no recommendation as to the compression required to obtain optimal imbrication. Given the aforementioned considerations, the following questions arise: a) Will the intensity of the applied vertical force modify the tensile strength? b) Will the removal and repositioning of the abutments influence their retention? The present study addresses the latter.

\section{Material and methods}

In this study, two commercial brands of Morse taper implant systems, Kopp ${ }^{\circledR}\left(\operatorname{Kopp}^{\circledR}\right.$, Curitiba, PR, Brazil) (Figure 1) and Bicon ${ }^{\mathrm{TM}}$ (Bicon Inc., Boston, MA, USA), were analyzed, both with implant-abutment sets accomplished by mechanical and frictional imbrication. They have a 1.23-1.5 degree tapered post that fits into a mirror-image shaft, with no screw.

An implant and an F II straight abutment model were selected from the Kopp ${ }^{\circledR}$ company measuring 4.3 x $13 \mathrm{~mm}$ and $4.5 \times 13 \mathrm{~mm}$, respectively. Similarly, an implant and abutment set was selected from the Bicon ${ }^{\mathrm{TM}}$ company measuring $4.0 \times 11 \mathrm{~mm}$ and $4.0 \times 6.5 \mathrm{~mm}$, respectively (Figure 1). For each set, a rigid base was fabricated consisting of a bolt (M $12 \times 1.25 \mathrm{~mm}$ ) with a hole at the top drilled with a mechanical lathe with the appropriate diameter to fit each implant tightly. To obtain the greatest possible resistance, a metal anaerobic adhesive (Three Bond 1375 - ThreeBond of Brazil Ltda) was used.

The sets were fixed individually in a Universal Testing Machine (DL 500 Emic - Equipment and Testing Systems Ltd., PR, Brazil). Then, they were connected to a load cell (Model CCE5KN - Emic) with a capacity of $5000 \mathrm{~N}$ at the machine's lower section. A weight (BCP, Kopp ${ }^{\circledR}$, Curitiba,
PR, Brazil) was used to generate compressive load. This device consisted of a constant-length $(0.065 \mathrm{~m})$ metal rod weighing $0.188 \mathrm{~kg}$. It was set in the upper part of the machine in a position concentric to the impact body trajectory to promote the attachment of the abutment to the implant (Figure 2).

In the first phase of the experiment, the abutment-implant sets were activated four times each by means of compressive force. Briefly, a single operator positioned the abutment over the implant without any pressure. Next, engagement between the complementary tapered surfaces of implant and abutment was accomplished by the impact of the body weight, dropped from a known height $(\mathrm{h}=0.065 \mathrm{~m})$, limited by the instrument. The force was applied along the long axis of the implant.

In the second phase of the experiment, the abutment of each set was fixed to a forceps shaped device connected to the same load cell, but now in a reversed position, on the upper part of the Universal Testing Machine (Figure 3). Next, the sets were subjected to a tensile force in the same machine until the abutment-implant assembly was displaced. The tensile force values required for the removal of abutment were recorded.

In the last phase of the experiment, the abutments were removed and reseated again three times, summing four reseating/removal cycles. At each displacement of the abutment, the tensile force necessary to remove was recorded, enabling an evaluation of whether the applied tensile force was greater than, equal to, or less than that obtained the first time. Thus, it was checked whether the removal and repositioning of the abutments increased the friction and therefore the retention values, or if there was a friction loss and consequent loss of retention.

\section{Results}

In the first phase of the experiment, the compressive load applied by the weight $(0.188 \mathrm{~kg})$ on the Kopp ${ }^{\circledR}$ and Bicon $^{\mathrm{TM}}$ abutment-implant sets was measured by the load cells. The experiment was performed under identical conditions for both brands. There were four activations in

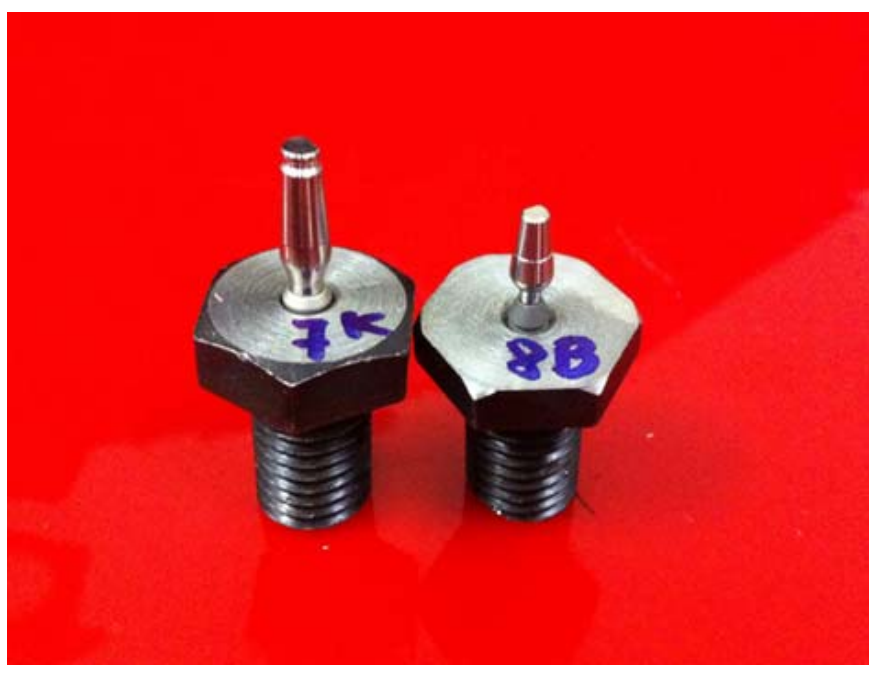

Fig. 1: Kopp ${ }^{\circledast}$ and Bicon ${ }^{\mathrm{TM}}$ implant-abutment sets fixed to a rigid base. 


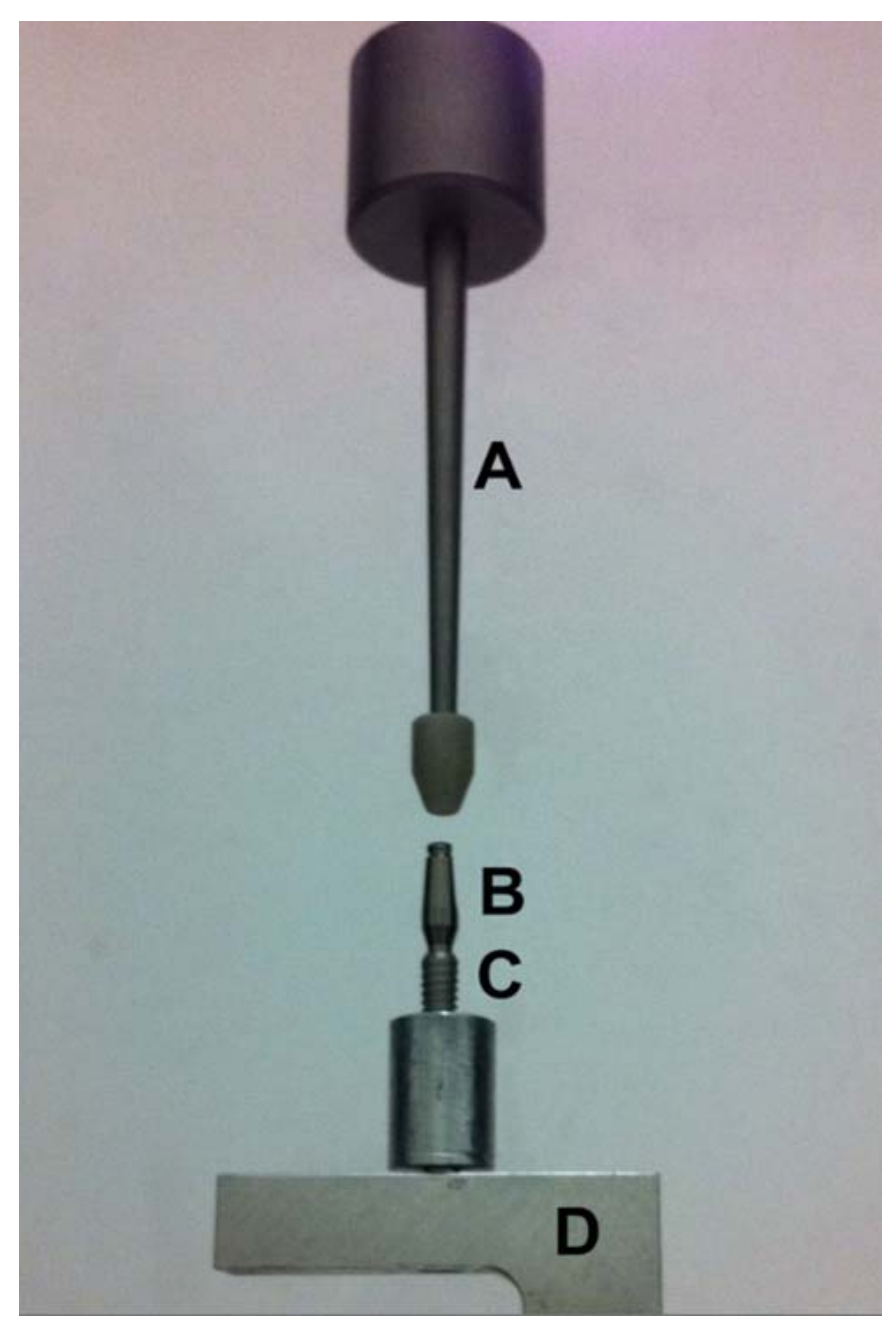

Fig. 2: Implant-abutment set positioned in the Universal Testing Machine for compressive test. A: weight in position; B: abutment; C: Implant; D: Load cell.

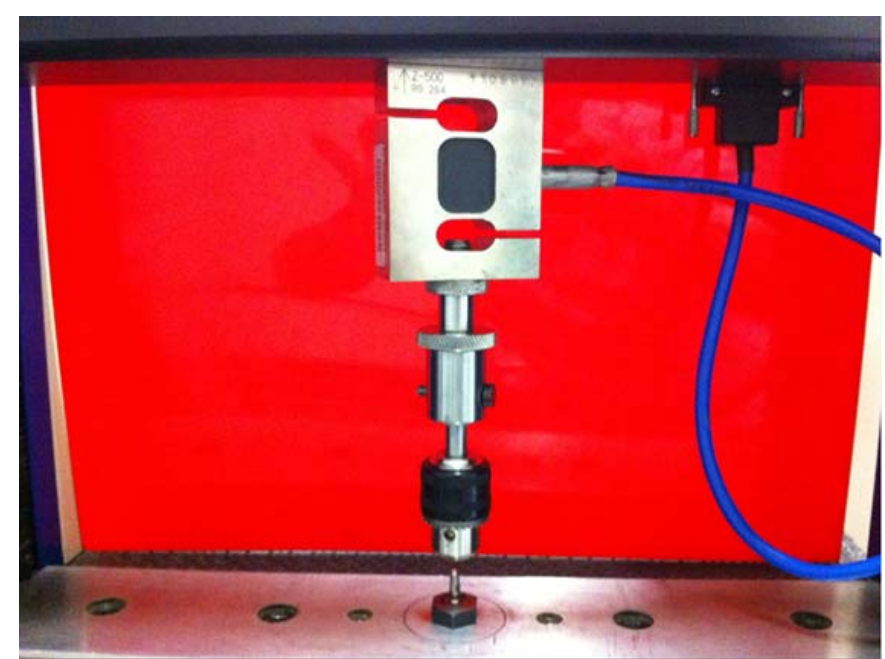

Fig. 3: Implant-abutment set positioned in the Universal Testing Machine for tensile test.

each set and the total results were $17 \mathrm{~N}$ for the Kopp ${ }^{\circledR}$ set and $21 \mathrm{~N}$ for the Bicon ${ }^{\mathrm{TM}}$ set.

In the second phase of the experiment, tensile loads were applied under identical conditions on the two implant- abutment sets. It was observed that the Bicon ${ }^{\mathrm{TM}}$ system presented a $208 \mathrm{~N}$ resistance and the Kopp ${ }^{\circledR}$ system, $194 \mathrm{~N}$.

In the last experiment, when new compressive and tensile loads were re-applied three times, it was possible to measure the following tensile values: $367 \mathrm{~N}, 500 \mathrm{~N}$ and $756 \mathrm{~N}$ for the Bicon ${ }^{\mathrm{TM}}$ system and $336 \mathrm{~N}, 360 \mathrm{~N}$ and $420 \mathrm{~N}$ for the Kopp ${ }^{\circledR}$ system.

\section{Discussion}

This study aimed to investigate whether the removal and reseating of the abutment influences the Morse taper implant system retention. High success rate in Morse taper implant systems has been reported ${ }^{9,15,17-18}$. However, an implant treatment may be hampered by complications, abutment displacement may occur ${ }^{9}$ and removal of the abutment may be necessary. This raises the question of whether the reinsertion procedure will risk the system retention ${ }^{17}$.

The present study showed that the tensile strength was proportional to the seating force applied to the abutment. In the Kopp ${ }^{\circledR}$ system implant-abutment set, in which the impact force was lower $(17 \mathrm{~N})$, the force to remove the abutment was $194 \mathrm{~N}$. In the Bicon $^{\mathrm{TM}}$ set, with a greater seating force $(21 \mathrm{~N})$, the force required to pull out the abutment was 208 $\mathrm{N}$, in the same conditions. These findings are in agreement with the statement that locking taper systems, when inserted into the implant, require a removal force greater than the insertion force?

In the final test, when the abutments were removed and then inserted three more times, tensile strength values of $367 \mathrm{~N}, 500 \mathrm{~N}$ and $756 \mathrm{~N}$ were obtained with the Bicon ${ }^{\mathrm{TM}}$ system and $336 \mathrm{~N}, 360 \mathrm{~N}$ and $420 \mathrm{~N}$ with the Kopp ${ }^{\circledR}$ system. According to these results, Bicon ${ }^{\mathrm{TM}}$ and Kopp ${ }^{\circledR}$ implant systems, when subjected to the same compressive loading conditions, had similar behavior. It means that the greater the applied compression, the greater is the tensile strength, although the obtained values were different.

Previous research has shown a positive correlation between the number of tappings and the removal forces for a locking taper implant system ${ }^{9}$, which is consistent with our findings. In fact, these results may be explained by the phenomenon of superficial hardening, which is the increased induration of the outer and inner surfaces of the implant and abutment, varying according to the elasticity of each metal alloy. With greater impact force there is a tendency of the abutment to undergo superficial plastic deformation on its platform (Figure 4a).

Additionally, our results can be explained by the phenomenon of the buckling of the abutment. When compressing a rod with a large diameter, a slight inclination along the axis is produced (Figure $4 \mathrm{~b}$ ). Finally, these results can also be explained by the fact that the tension between the surfaces tends to be asymptotic, due to their angulation, which creates a non-uniform distribution of the compressive stresses and consequently changes the cross-sectional rigidity (Figure $4 \mathrm{c}$ ). Therefore, the tensile strength should increase as the compressive force increases. When these phenomena 


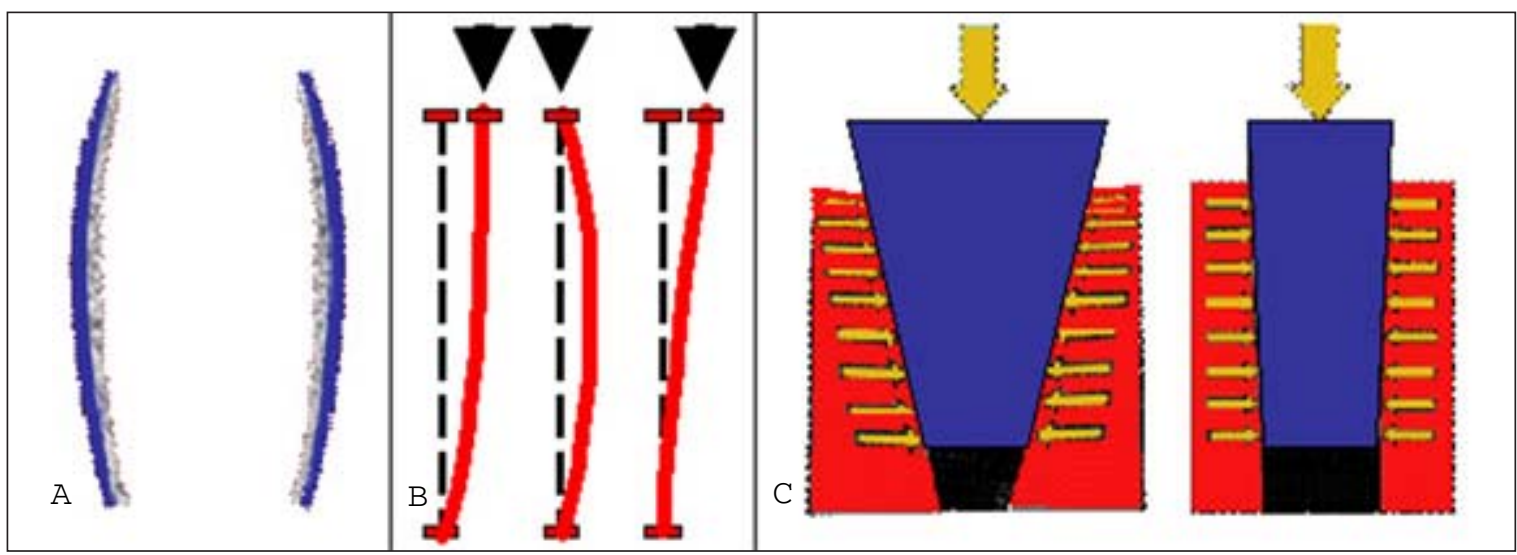

Fig. 4: Schematic drawings: a) superficial hardening; b) buckling; c) asymptotic tension superficial induration.

occur, the individual compressive force may not be concentric, generating a variable compressive load. Although this increase in surface rigidity could be interesting, cracks may occur, which is an undesirable effect ${ }^{20}$.

It should be mentioned that in vitro study models might not predict the clinical reality. There are many factors influencing in vivo implant components placement and behavior. As a matter of fact, this in vitro study did not consider bending forces, usual in a clinical situation, which may alter the abutment resistance to displacement. Furthermore, to the extent of our knowledge only the two systems analyzed in this work use a tapered interference fit solely. Thus, it is difficult to compare our data with other researches. In a recent systematic review about conical abutment connection implants, the majority of the Morse taper implant system designs included a screw ${ }^{4}$. Nonetheless, this experimental work sheds light on the influence of abutment reseating on the retention of Morse taper implant systems. Although only one sample of each implant system was used, the mechanical tests revealed a clear tendency with important practical application.

In the present study, we observed that higher compressive forces generated higher tensile strength. The results obtained in this study reveal that the removal of the abutment and subsequent repositioning for a total of four repetitions increased the tensile force required to remove the abutment, thereby increasing its frictional retention. Within the limits of this in vitro study, the reseating of abutments in locking-taper implants seems to be a successful procedure. Further research is necessary to clarify the clinical relevance of our findings, and to establish the optimum compressive force for each commercial brand that uses exclusively the Morse taper fixation system to connect implant and abutment.

\section{Acknowledgements}

This work was supported by grants from CAPES, Brazil; CNPq, Brazil; Fundação de Amparo à Pesquisa do Estado de Minas Gerais (FAPEMIG), Brazil. SVO is a Capes fellow.

\section{References}

1. Pita MS, Anchieta RB, Barão VA, Garcia IR, Pedrazzi V, Assunção WG. Prosthetic platforms in implant dentistry. J Craniofac Surg. 2011; 22: 2327-31.

2. Sannino G, Barlattani A. Mechanical evaluation of an implant-abutment self-locking taper connection: finite element analysis and experimental tests. Int J Oral Maxillofac Implants. 2013; 28: e17-26.

3. Mangano F, Macchi A, Caprioglio A, Sammons RL, Piattelli A, Mangano C. Survival and complication rates of fixed restorations supported by locking-taper implants: a prospective study with 1 to 10 years of follow-up. J Prosthodont. 2014; 23: 434-44.

4. Schmitt CM, Nogueira-Filho G, Tenenbaum HC, Lai JY, Brito C, Döring $\mathrm{H}$, et al. Performance of conical abutment (Morse Taper) connection implants: a systematic review. J Biomed Mater Res A. 2014; 102: 552-74.

5. Yamanishi Y, Yamaguchi S, Imazato S, Nakano T, Yatani H. Influences of implant neck design and implant-abutment joint type on peri-implant bone stress and abutment micromovement: three-dimensional finite element analysis. Dent Mater. 2012; 28: 1126-33.

6. Wittneben JG, Buser D, Salvi GE, Bürgin W, Hicklin S, Brägger U. Complication and failure rates with implant-supported fixed dental prostheses and single crowns: a 10-year retrospective study. Clin Implant Dent Relat Res. 2014; 16: 356-64.

7. Junqueira MC, Ribeiro RF, Faria ACL, Macedo AP, Almeida RP. Screw loosening of different UCLA-type abutments after mechanical cycling. Braz J Oral Sci. 2013; 12(3): 228-32.

8. Jung RE, Zembic A, Pjetursson BE, Zwahlen M, Thoma DS. Systematic review of the survival rate and the incidence of biological, technical, and aesthetic complications of single crowns on implants reported in longitudinal studies with a mean follow-up of 5 years. Clin Oral Implants Res. 2012; 23(Suppl 6): 2-21.

9. Chapman RJ, Grippo W. The locking taper attachment for implant abutments: use and reliability. Implant Dent. 1996; 5: 257-61.

10. Shepherd NJ. Affordable implant prosthetics using a screwless implant system. J Am Dent Assoc. 1998; 129: 1732-38.

11. Keating K. Connecting abutments to dental implants: "an engineer's perspective". Irish Dent. 2001: 43-6.

12. Assenza B, Tripodi D, Scarano A, Perrotti V, Piattelli A, lezzi G, et al. Bacterial leakage in implants with different implant-abutment connections: an in vitro study. J Periodontol. 2012; 83: 491-7.

13. Silva-Neto JP, Majadas MFF, Prudente MS, Carneiro TAPN, Penatti MPA, Neves FD. Bacterial microleakage at the implant-abutment interface in Morse taper implants. Braz J Oral Sci. 2014; 13: 89-92.

14. do Nascimento C, Miani PK, Pedrazzi V, Gonçalves RB, Ribeiro RF Faria $A C$, et al. Leakage of saliva through the implant-abutment interface: in vitro evaluation of three different implant connections under unloaded and loaded conditions. Int J Oral Maxillofac Implants 2012; 27: 551-60. 
15. Nentwig GH. Ankylos implant system: concept and clinical application. J Oral Implantol. 2004; 30: 171-7.

16. Feitosa PC, de Lima AP, Silva-Concílio LR, Brandt WC, Neves AC. Stability of external and internal implant connections after a fatigue test. Eur J Dent. 2013; 7: 267-71.

17. Urdaneta RA, Marincola M, Weed M, Chuang SK. A screwless and cementless technique for the restoration of single-tooth implants: a retrospective cohort study. J Prosthodont. 2008; 17: 562-71.

18. Norton MR. An in vitro evaluation of the strength of an internal conical interface compared to a butt joint interface in implant design. Clin Oral Implants Res.1997; 8: 290-8.

19. Zielak JC, Rorbacker M, Gomes R, Yamashita C, Gonzaga CC, Giovanni AF. In vitro evaluation of the removal force of abutments in frictional dental implants. J Oral Implantol. 2011; 37: 519-23.

20. Gere JM, Timoshenko SP. Mechanics of materials. Boston: PWS Pub Co.; 1997 